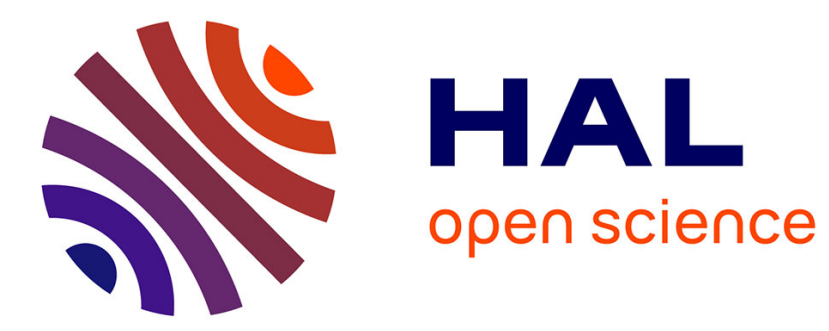

\title{
Graphical modelling for geographic explanation
}

Jean-Paul Cheylan, Thérèse Libourel Rouge, Cornelius Mende

\section{To cite this version:}

Jean-Paul Cheylan, Thérèse Libourel Rouge, Cornelius Mende. Graphical modelling for geographic explanation. COSIT: Conference on Spatial Information Theory, Oct 1997, Pennsylvania, United States. pp.473-483, 10.1007/3-540-63623-4_68. hal-02266694

\section{HAL Id: hal-02266694 \\ https://hal.science/hal-02266694}

Submitted on 19 Aug 2019

HAL is a multi-disciplinary open access archive for the deposit and dissemination of scientific research documents, whether they are published or not. The documents may come from teaching and research institutions in France or abroad, or from public or private research centers.
L'archive ouverte pluridisciplinaire HAL, est destinée au dépôt et à la diffusion de documents scientifiques de niveau recherche, publiés ou non, émanant des établissements d'enseignement et de recherche français ou étrangers, des laboratoires publics ou privés. 


\title{
Graphical Modelling for Geographic Explanation
}

\author{
Jean-Paul Cheylan*, Thérèse Libourel** and Cornelius Mende* \\ *CNRS-UMR ESPACE and GdR MIS-CASSINI \\ Maison de la Géographie \\ 17 rue Abbée de l'Epée \\ 34000 Montpellier, France \\ Phone: +33 4 67145858; Fax: +33 467726404 \\ cheylan@mgm.fr; mende@mgm.fr \\ **CNRS-UMR LIRMM and GdR MIS-CASSINI \\ 161 rue Ada \\ 34000 Monpellier, France \\ libourel@lirmm.fr
}

Directly interpretative spatial knowledge which may be of value to the user resides in the possible arrangements underpinned by geographical objects. Until now, the meaning of geographic information was unveiled through the eye-brain apparatus of the user. The challenge consists in capturing such meaning by finding the significant dimensions which structure the diversity of the informational space, and which are used to perceive, and as much as possible explain, highly significant spatial arrangements and organisations bearing their own signification.

\section{Introduction}

"There are two ways of wandering in a forest. You either wander trying several paths or you wander trying to understand how the forest is formed, why some paths are accessible and others are not." Umberto Eco

We plan to build an adaptive diagnostic geographic information system whose purpose is to improve the mechanisms for interactively accessing the meaning of geographic information. With the use of methods based on advanced database and multimedia information technology, the system should be able to assist the interpretation of cartographic, textual, and graphic documents which are linked together through argumentative explanation. This information system involves various data subsets defined by the user inside of a given geographical space. Social, economical and environmental management of such spaces normally requires the action of various agencies, in charge of producing local studies covering areas which vary in extent and structure. Queries may be addressed to various thematic layers, to various levels of organisation and may concern various periods. The users should have the opportunity to access the analytical tools specific to their needs. The embedded interpretative spatial knowledge system should provide direct access to geographic information at the highest level, that of structural interpretation. The 
information links are made accessible through structural and process-tracing schema, hereafter named choremes.

\section{Naive Geography and Geographical Explanation}

Directly interpretative spatial knowledge which may be of value to the user resides in the possible arrangements underpinned by geographical objects. Until now, the meaning of geographic information was unveiled through the eye-brain apparatus of the user. Generally, geographical information systems involve various data sets covering a given geographical space. The user's view of the content is mainly available through cartographic representations. The classes presented in a legend correspond to a very poor semantic level, without historic, thematic, or, indeed, inter-thematic explanation of the observed organisations.

The challenge consists in capturing such meaning by finding the significant dimensions which structure the diversity of the informational space, and which are used to perceive, and as much as possible explain, highly significant spatial arrangements and organisations bearing their own signification. An example of such patterns is given by the concentric rings shaping an urban system, delineating the successive urban growth periods.

\section{Spatial Reasoning and Geographical Explanation}

Our proposal is quite different from the so-called "Naive geography" and "spatial reasoning" perspectives. Explanatory geography deals very little with the qualitative interpretation of common sense locational, directional and relational terms. That kind of knowledge is assumed to be regularly integrated in the domain-consensual common-sense understanding of the user.

As for geographical explanation (Harvey 1969, Gregory 1978) we define it here as a process which identifies and combines spatial and spatio-temporal structures and patterns. This process is grounded on structural, mainly analogical reasoning. Interstructural analogies are made between spatial elements, presenting morphological, thematical or inter-structural analogy. This leads to the association of different structures, identified as different instances of the same archetypal situation or model (an estuary system, a pair of towns on either side of a river, the hierarchical structure of a valley and its mountainous relief, etc.). Any archetypal situation draws on the problem of it's development, based on the relatively regular and limited set of human cultural and social adaptative responses. The diversity of the observable situation is a result of the very large number of combinations of elementary structures, and of the diversity of the historically layered traces and re-use of existing structures. Some inter-organisational levels of reasoning occur, where the same pattern is active at different organisational levels (scales), leading to iterative, recursive or even fractal spatial situations (from local valleys to the main-stream system, or from the coreperiphery village organisation to the whole metropolitan system). Inductive reasoning here is strongly combined with specialised, domain specific semantic argumentation leading to the primary identification of patterns and their consensual 
denotation. As a validation process deductive reasoning is involved, mainly as an heuristic method allowing the production of complementary explanations.

\section{Choremes}

A relatively limited but elementary set of archetypal spatial organisations or spatiotemporal processes (Figure 1 table Choremes) can be used to represent, directly or via combinations, the explanation and argumentation of complex spatial organisations. The argumentation process works mainly by accumulation of non contradictory arguments (what is understood, how is it understood). The system will propose a quantitative argumentation based on the semantics appropriate to the given project. The user will be able to contribute to the proposed basic interpretation. Access to the global information may be realised starting from the outside layer which is semantically most relevant and which will take the form of a privileged navigator (browser). This navigator is based on the concept of the choreme, which we can define as follows:

a) Modelling a space (in the sense of graphical modelling through the production of choremes) means seeking a fundamental structure and its causal and dynamic aspects. It does not mean summarising or generalising; rather smoothing out the singularities in order to extract the principles involved and formulate an hypothesis.

b) A spatial configuration is the result of a complex combination of simple mechanisms. These correspond to the solutions which society currently must find to resolve the problem of space management and to the physical forces with which societies must reckon.

c) This configuration can be best understood through the combination of elementary structures expressed in choremes. Each choreme is a sign, with a given form and meaning. The meaning reflects a process. Therefore the use of such and such a choreme to represent a geographical configuration is not a coincidence, rather, the choreme reflects a process, an organisation or structure with it's proper dynamic. (R. Brunet, 1986, Mappemonde N. 4). Hence a choreme is a powerful tool of knowledge representation due to its ability to symbolise and encapsulate a methodology and a corresponding interpretation.

Every situation which may be observed can be discussed on the basis of its spatial, statistical and temporal context beginning with the maps and the background attribute tables which are usually available, and which serve as information layers for the analysis. In the same way, the arguments which are expressed through the interpretation of these documents can be analysed, in order to produce semantic graphs or other graphs originating from various statistical techniques such as correlation, covariance, and auto correlation. These graphs can also be used to build an adaptive network for the exploitation of the documents in order to produce relevant argumentation. 
Chorèmes

Ir. 1

Elenertary features
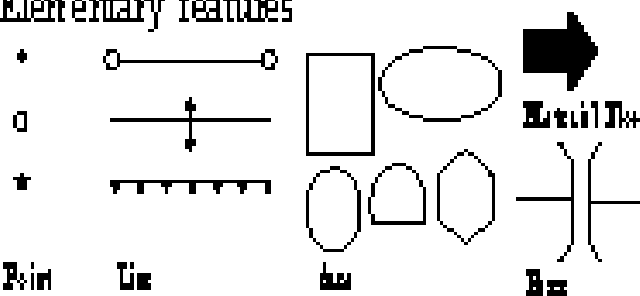

$+1=$

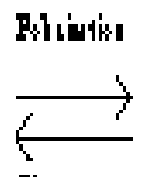

Min tir

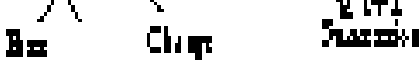

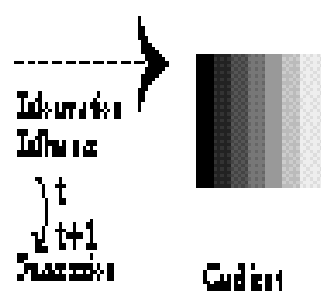

Choremes

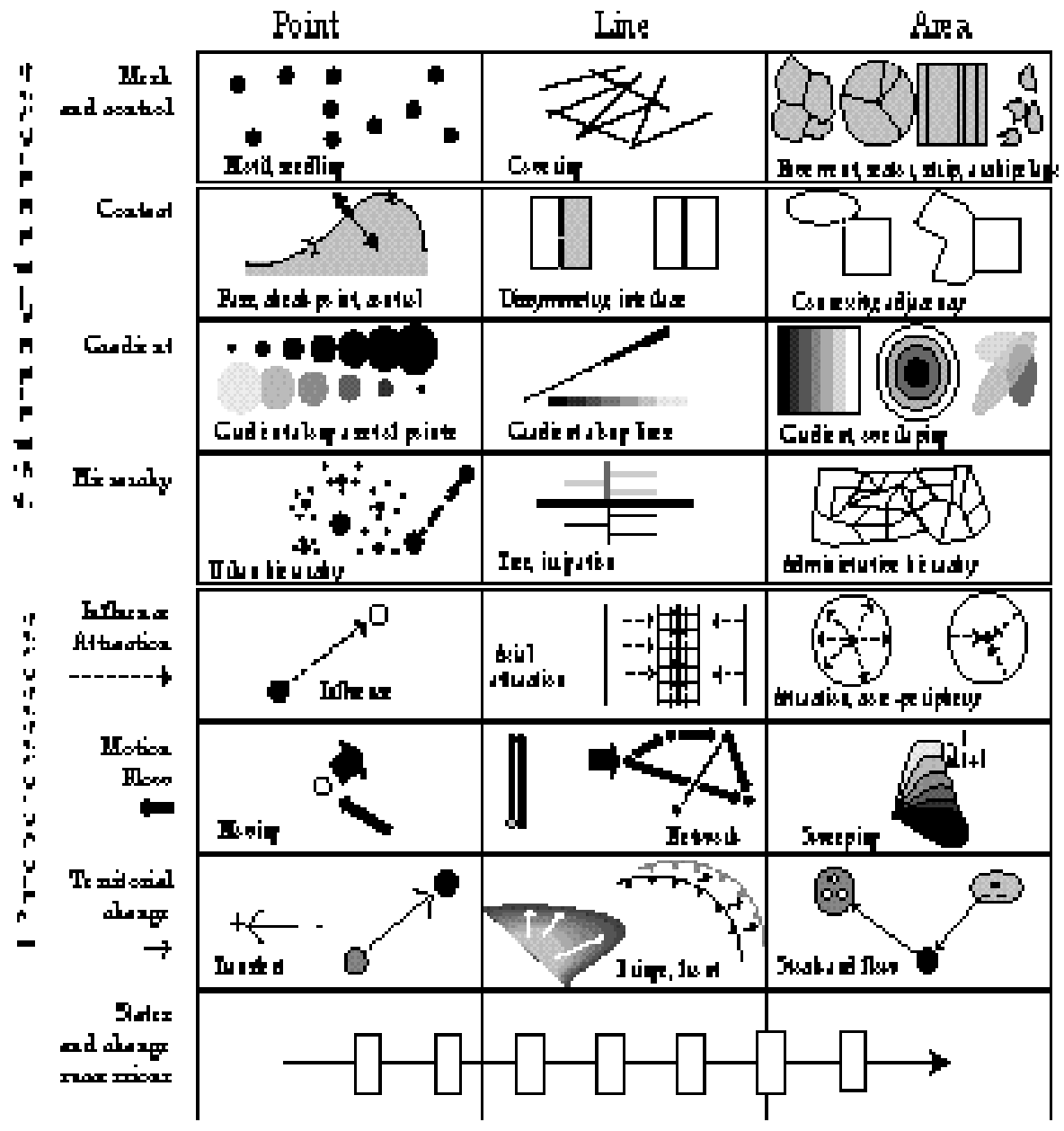




\section{Example: «Alès Inside the Languedoc Gradient »}

As an example, the determination of the general population growth structure of a small region with relative low density centred on the city of Alès (Gard, France), will be briefly presented. The population structures are organised in successive growth rings. These concentric rings are sometimes irregular, such as around Alès, for example. They can be explained through their history. The most active urban periphery has either a ring structure developed around urban poles, or propagates itself along axes which integrate a group of villages or small towns characterised by rapid growth along the main regional communication lines (Figure 2).

\section{Proposed Organisation}

\section{Information Collected}

The object is the basic element, simultaneously understood as a significant geographical object and as an object pertaining to an object-oriented data base. Objects are elements which constitute the basic geographical information.

\section{Spatial Objects}

Points, lines and areas are the basic spatial entities. They are used to build the basic sets (layers, complex sets, etc.) through the exploitation of complex relations. In our example, towns, their scattered rings, and low density areas constitute the basic objects. They can be used to enrich the adaptive construction of a visual message using the usual techniques of statistical cartography in $2 \mathrm{D}$ and $3 \mathrm{D}$, static or animated.

\section{Statistical Objects}

The basic object of statistical systems is the table, a matrix of information describing places and their various attributes. Significant indicators, rarely available in the background information, are derived through calculations. Other statistical objects may be necessary, such as graphs, flow diagrams, correlation, and other statistical meta data.

\section{Textual Objects}

The textual objects may have different functions: they may serve as a complement to the cartographic representations (legends, textual annotations or attribute values of the spatial entities), or as comments to objects, methods, graphs, and argumentative reports.

\section{Meta data}

The meta data represent the highest abstract level of the information. They concern at least the following three basic aspects :

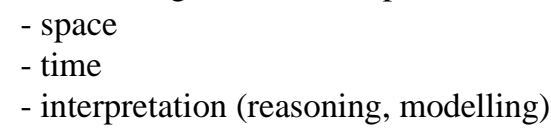


figure 2: A brief choreme frm the Alès region The Mediterranean amphitheatre: a set of concordant gradients (altitude, population density, climate, agricultural resources).

Urban and administrative hierarchy, a linear hierarchy set back from the littoral. A second set of small and middle towns along the piedmont including Ales. Located underneath a former refuge belonging to a religious minority in the mountains.

Settlement history: the former industrial piedmont (hydraulic power) has produced a set of industrial towns along the 18th and 19th century. The 20th century rural migration ( 3 stages) induced a growth and recently a decline of population. Today a very scatered population growth occurs in the rural regions.

The town functions as a contact between two gradients: the Mediterranean mountains (Cevenne) and the hills and plain littoral regions. Ales is an important market. As contingent conditions develop, a geological fault places resources near. The town has had an important extractive function until 1960.

The town is organised via classical rings (age of the settlement and the population) and a sector structure (social segregation system). Upper classes are located in a quiet hilly zone. The lower classes remain close to the extractive and industrial areas.

Contingent conditions limit the growth and the urban structure to three sectors. The largest, to the north-east, combines an aged population retired from mining activities and an active industrial population. The plain, in the south-west, is occupied by commercial settlements around the Nimes road. The western sector is residential.

In the two main growth sectors some villages are affected by a periurban growth, producing axial zones. Some are linked together along the piedmont depression and along the main regional axis (Nimes, Montpellier), giving the perception of a linear growth system.
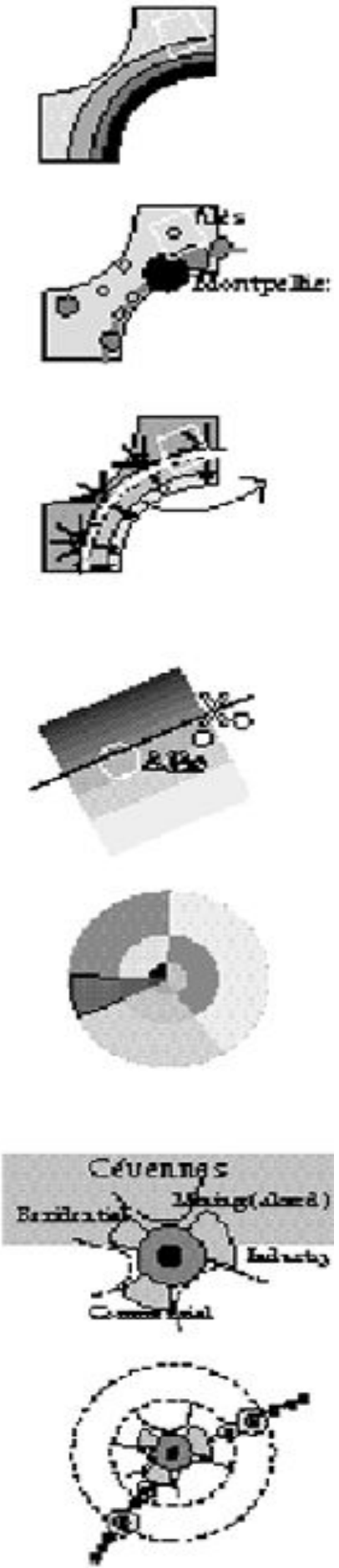
The meta data borrow their structure from other types of objects and describe the fundamental structural, indeed dynamical, aspects of the information. They belong to a particular class of objects.

\section{Composition and Derivation}

- Composition and derivation, methods and objects. Geographic information can be structured with the help of composition relations which put together the building blocks of information: those relations are normally implemented in GIS and spatial data bases. Complex objects are also integrated. But they must be enriched by the semantic relations and descriptions which make possible the definition of aggregated classes from which organisation layers can be derived.

\section{Presentation Level}

\section{Interpretative Structures}

Some large divisions which organise the information emerge from the simultaneous use of the objects and their composition; these are the most useful organisation schemes to access the information, and to depict the knowledge embedded in the "choremes".

\section{Levels of Organisation}

Parcels, eco-entities,... global world, all these levels involve various types of spatial organisation. The various levels of cartographic generalisation lead to alternative displays, polygon or point for a town for example. The levels of statistical aggregation contribute to the definition of organisation levels, such as the various levels of generalisation of nomenclatures. Thus our goal is the construction of various levels of geographical organisation, strongly related to the problems at hand. These levels characterise the sets of objects which share a similar level of organisation, with an identified semantic recognised in the interpretative discourse (e.g. small urban regions, morphological units based on the landscape,...etc.).

\section{Thematic}

The electors or the nitrate...The thematic universe, perceived as the main key to the selection of information, must be structured in various ways, depending on what we search for in the conventional academic disciplines: geography (human, physical, regional...), economy (urban, rural, services), sociology, geology, pedology, agronomy, etc., including their divisions, schools of thought, contradictions and incoherence. The main classes of queries which are at the origin of potential applications are probably the most pertinent to address, such as the study of the structure and dynamics of population settlements, of urban concentrations, or the management of the environment and the interactions between social and natural systems.

The Social Functions of Objects ( ̀̀ la Erik Stubjaer ) 
Social processes give birth to geographical objects: the legal definition of a parcel, urban zoning, the scientific interpretative reasoning of an analyst, perceptual processes such as the designation "lieu-dit"; or mountainous regions. The nature of these processes conditions the extent of the domain of validity of the objects. An object can change it's status all along its life: a zoned region is first of all an analytical region for planners, then it becomes an administrative legal zone, and finally will be socially recognised as a new part of the town, with its own name.

\section{The Temporal Dimension}

The temporal dimension is necessary for the interpretation of past and present processes based on Time, or to identify tendencies.

The spatio-temporal relations between objects, which are characterised by the level at which modifications are made, are necessary in order to understand active processes. They are represented by lineage and updating mechanisms concerning the identity of an object, the value of an attribute, the attribute itself, the graphical data associated with the objects, the dependencies between object families, and by data schema. The Time of the data base (physical Time, also called transactional Time) is associated with the observed evolution (valid Time).

\section{Information Building Process}

In the proposed system, the different levels of the information building process from the raw data to the interpretative schema will be made accessible, all along the argumentation chain, containing rules and methods used for the identification of argumentative, statistical, spatial or interpretative relations. From an adaptive and dynamic point of view, the information will be easily enriched, updated, and improved. Furthermore, the system will be able to incorporate new information brought in by the user.

\section{Symbolisation Level}

\section{Symbolisation Methods}

Based on a set of rules from graphical semiology (Bertin, 1967,; Brunet, 1984, La carte mode), the symbolisation methods will have to be tuned depending on the quality of the display tools and improved according to the new possibilities made available by the progress of computer graphics: dynamic display, display in three or four dimensions

\section{The choremes}

They can be considered as language elements used to represent and describe spatial knowledge. From this perspective, they provide the user with enriched knowledge in the final graphical model (fig. 3). 


\section{Semantic Presentation}

The semantic presentation is based on the dynamic, actionable, graphical representation of symbolised, communicative structure through choremes. From the point of view of semantic presentation, the choremes are powerful tools of communication; because of their synthetic structure, they form a discourse highly condensed but strongly loaded with semantic information. They can be used to communicate the spatial meaning perceived by the expert. They are strongly dependent on a type of expertise which is normally not explicitly available. We propose here to join the interests of the user and the analysis of her/his activities with tools which can generate adaptive queries about the information at hand (wellconceived choremes have been valued by the expert who considers that they bring an argument which appears inevitable and which should have been already obvious).

\section{Interpretation Methods}

Two types of techniques will be used, one traditional, the other more innovative. The first class of techniques is based on descriptive statistics, geographic modelling, spatial queries within GIS, etc. The second class of methods is related to artificial intelligence tools such as semantic networks, and spatial configuration learning. These methods will provide a generic capability to the system.

Only part of the geographical discourse, whether for explanation or interpretation, can be made explicit or formalised. A first step, which is exploratory and uncertain, leads the analyst from the background data to a first attempt of explanation. The methods used for this purpose are multiple, sometimes contradictory, and depend on the expert who is responsible for the study. They cannot be applied directly, although this could be envisaged in the longer term.

\section{CONCLUSION}

Choremes and the graphical method of modelling based on choremes have already proved their efficiency [Brunet, Grataloup]. A new perspective consists of their integration and automation within geographic information systems which will lead to the formalised emergence of spatial reasoning and interpretation. The decisionmaking process will then be enhanced while enriching and refining operational knowledge.

\section{Acknowledgement}

Thanks are extended to Jean-Claude Muller, Geoffrey Edwards, Andrew Frank, Erik Stubjear, and Gérard Ligozat for their helpful comments on the preliminary version of the paper and/or their help for the task of improvement of the translation from French into English. 


\section{References}

Bertin J. 1981, Graphics and graphic information processing, de Gruyter, Berlin.

Brunet R. 1980, Building models for spatial analysis in Two decades of l'Espace Geographique, Montpellier, GIP RECLUS, 1993. First published in 1980 as La composition des modèles dans l'analyse spatiale, L'Espace Géographique, Paris, No. 4.

Brunet R. 1987, La carte, mode d'emploi, Paris, Fayard/RECLUS.

Brunet R., 1990, Mondes nouveaux, Géographie Universelle, Vol.1, Ed. Belin/RECLUS.

Cheylan J.P., Desbordes-Cheylan F., Farinas L., Faure A., 1981 Geo: Un système pour la représentation des connaissances spatiales in Actes: 4ième congrès AFCET. Reconnaissance des formes et intelligence artificielle, Paris, Janvier.

Cheylan J.P., 1986, Les Cévennes: anatomie d'une fracture, Mappemonde, No. 4, pp. 30-33.

Cheylan J.P.,Deffontaines J.P., Lardon S., Thiery H., 1990, Gestion de l'espace rural, des pratiques aux modèles, Mappemonde, No. 4-90.

Deffontaines J.P., Cheylan J.P., Lardon S., 1990, Gestion de l'espace rural, des pratiques aux modèles, Editorial, Mappemonde, No. 4-90.

Cheylan J.P., Deffontaines J.P., Lardon S., Thiery H., 1990, Les chorèmes: intérêts et limites pour l'étude de l'activité agricole dans l'espace rurale, Mappemonde, No. 4-90.

Cheylan J.P., Deffontaines J.P., 1990, Interactions, modèles, modelage: Cévennes, Mappemonde, No. 4-90.

Cheylan J.P., 1992, Are specific GIS functions required for geographical data processing in the social sciences?, Workshop ESF-GISDATA, Sintra, 10-13 Juin.

Cheylan J.P., et Equipe S.I.G.,1995, Diagnostic et aide à la décision pour la gestion d'espaces à faible densité démographique de la région Languedoc-Roussillon, Rapport intermédiaire, GIP Reclus, December.

Cheylan J.P., 1996, Time and Spatial Databases, Toward a Conceptual Application Framework, Workshop ESF-GISDATA, Greece, May.

Gregory D., 1978, Ideology, Science and Human Geography, Hutchinson Univ. Library, London.

Harvey D., 1969, Explanation in Geography, Edward Arnold, London 